\title{
Pilates plus cardiovascular training in body composition: effects of adding continuous cardiovascular training to the pilates method on adult body composition
}

\begin{abstract}
Introduction: The Pilates method shows several benefits to the health include to the free fat body mass. In another hand, data about the combined training, pilates plus cardiovascular continuous training, up to body composition is scare.
\end{abstract}

Objective: To investigate whether or not continuous cardiovascular training added to the pilates method modifies the body composition of young adults.

Methodology: A group of 30 volunteers was selected and randomly separated into two groups of fifteen people: Cardiovascular Experimental Group (CEG) and Control Group (CG). Then, both underwent sixteen weeks of Pilates training with twenty reps, sixty seconds apart. The CEG performed ten minutes of continuous cardiovascular training at $75 \%$ of maximal heart rate (HRmax). Body mass, height and waist circumference (WC) were measured and Body Mass Index (BMI), Body Adiposity Index (BAI) and Waist-to-Height Ratio (WHtR) were calculated.

Results: The values obtained before and after tests for all of the variables of the present study suffered variation, although significant differences were found for WC and WHtR $(\mathrm{p}<0.05)$ in the CEG alone.

Conclusion: The association of ten minutes of continuous cardiovascular training with the Pilates method is able to decrease waist circumference and the waist-toheight ratio.

Keywords: Pilates, Continuous cardiovascular training, Body composition, Combines training
Volume 2 Issue I - 2018

\author{
Almir Araújo Marques,' Tatiane Roberta \\ Buratti Nogueira, ${ }^{2}$ Vernon Furtado da Silva, ${ }^{3}$ \\ Talita Adão Perini de Oliveira, ${ }^{4}$ Glauber \\ Lameira de Oliveira, ${ }^{4}$ Estélio Henrique \\ Martins Dantas, ${ }^{5}$ Patrícia Soares de Pinho \\ Gonçalves, ${ }^{6}$ José Fernandes Filho, ${ }^{7}$ Angeliete \\ Garcês Militão, ${ }^{8}$ João Rafael Valentim Silva ${ }^{8}$ \\ Manual Therapies and Kinesiotherapy, Brazil \\ 2Exercise Physiology and Personal Trainer, Brazil \\ ${ }^{3}$ Visiting Professor, Federal University of Rondônia, Brazil \\ 'Master's Degree, Human Motricity Sciences, LABIMH-UFRJ, \\ Brazil \\ ${ }^{5}$ Professor, Federal University Tiradentes, Braz \\ Department of Physical Education and Sports School, Federal \\ University of Rio de Janeiro, Brazil \\ Associate Professor, Federal University of Rio de Janeiro, Brazi \\ ${ }^{8}$ Professor, Federal University of Rondônia, Brazi
} Human Motricity Sciences, Professor in Federal University of Rondônia and the Lutheran Institute of Higher Education, Brazil, Tel 69992 I |30 I5, Fax 98|32963, Email p.jrvalentim@gmail.com

Received: November 02, 2017| Published: January 17, 2018
Abbreviations: CEG, cardiovascular experimental group; $\mathrm{CG}$, control group; HRmax, maximal heart rate; WC, waist circumference; BMI, body mass index; BAI, body adiposity index; WHtR, waist to height ratio

\section{Introduction}

Regular physical activity is associated with reduced risk of developing obesity among adolescents and adults ${ }^{1}$ and cardiovascular adaptations are well documented by different authors who associate them with a lower risk of developing diseases..$^{2-4}$ On the other hand, physical inactivity and a sedentary lifestyle are associated with the risk of developing different metabolic diseases such as diabetes and insulin resistance, ${ }^{5,6}$ cardiovascular diseases such as acute myocardial, ${ }^{7}$ Cerebrovascular accidents, different effects of aging, such as sarcopenia and osteoporosis, ${ }^{8}$ overweight and obesity, chronic inflammatory conditions, ${ }^{10}$ thus, it can be inferred that physical exercise can be considered an important measure in the prevention and cure of diseases. ${ }^{11-12}$ In this context, the study of body composition deals with the quantification of the structural components of the human body, divided into specific tissues that make up the total body mass. ${ }^{13}$ The study of body composition, especially with regard to fat and lean body mass, has become important among scholars to specify such proportions since fat accumulation in central regions is associated with an increase of risk factors for cardiovascular accidents highlighting the importance of this type of investigation.

Body composition and the measure of a tendency towards central fat accumulation, taken together, can denote quality of life and health showing the importance of this factor to the healthy and the quality of life. Following, when we talk about the Pilates, several articles came showing contradictory, but frequent, evidences that this method can modify the body composition of the overweight and obese women, ${ }^{3,13}$ in sedentary young women ${ }^{14}$ and in revert a few consequences of de ageing associated with an increased fat mass ${ }^{14,15}$ as example of the effects of the Pilates method upon the women body composition, but, in male people, the studs is less abundant and, the association of different approaches to complement this exercise modality is very rare. Previously, our group published a paper that describe the effect of Pilates Method upon the body composition that in fact the body fat related with the fat mass do not decrease. ${ }^{16}$ So, thinking about this problem, was planed an exercise association to solve the ineffectiveness in enhance the body composition by the Pilates method. Therefore, the objective of the present study was to identify whether or not the insertion of continuous cardiovascular training in sections of Pilates training modifies the body composition of a heterogenic group. 


\section{Methodology}

\section{Volunteer group}

A voluntary group of 30 subjects including both sexes was selected, with a mean age of $34.56 \pm 7.12$ years, body mass of $68.33 \pm 10.43 \mathrm{~kg}$ and height of $167.7 \pm 7.61 \mathrm{~cm}$. All volunteers voluntarily accepted to participate in this study. The volunteers were randomly divided into two groups: Cardiovascular Experimental Group (CEG) and Control Group (CG). Each group consisted of 15 individuals. The Human Research and Ethics Council from the Federal Institute of Education of Rondônia approved this investigation under number CAAE 44907715.2.00005653. All subjects consented to participate.

\section{Instruments and procedures}

Body mass and stature were obtained by means of a Filizolla mechanical platform scale with an accuracy of $0.1 \mathrm{~kg}$. Waist circumferences were measured at the smallest point of circumference between the iliac crest and the last rib and hip with a flexible metal tape measure, with an accuracy of $0.1 \mathrm{~cm}$. Based on these measurements it was possible to calculate the following parameters: Body mass index, Body adiposity index, Waist-to-Height ratio. Training control was monitored with the heart rate using the training target zone that was based on the equations proposed by Tanaka ${ }^{14,17}$ as described in the equations below. To monitor the heart rate during training, an FT1 Polar brand frequency meter was used. This conjunct of experiments was following the methodology described. ${ }^{17-20}$

$$
\begin{aligned}
& B M I=\frac{\text { Body mass }}{\text { Height } x \text { Height }} \\
& B A I=\left(\frac{\text { Hipcircumference }}{\text { Heightx } \sqrt{\text { height }}}\right)-18 \\
& W H t R=\frac{\text { Waist circumference }}{\text { Height }} \\
& \text { Lowerlimit }=(208-0.7 \times \text { age }) \times 72.5 \% \\
& \text { Lowerlimit }=(208-0.7 \times \text { age }) \times 77.5 \%
\end{aligned}
$$

Both groups underwent sixteen weeks of training, three times a week with a total duration of 60 minutes per training session. In the training protocol, for the CEG, prior to the Pilates session itself, ten minutes of mini-trampoline cardiovascular training was introduced at $75 \%$ of the HRmax as a warm-up working within the pre-established training target zone according to age. The cardiovascular training target zone was determined to be around $75 \%$ of maximal resting heart rate. The classes began with the flexibilization of the lower limbs, change and upper limbs for approximately ten minutes, then went to the work of strengthening them, with variations between heel and toe, rotation of the wrist to upper limbs with repetitions between 10 and 12 for each exercise and being 2 or 3 sets for lower limbs for women and for upper limbs men, the balance exercises and strengthening of the lumbar region in the apparatus as well as with balls and other accessories is made the variation of muscular contractions and isotonic, with repetitions of 10 and variations of time between 05 to 15 seconds. However the Abdominals are performed in series with a maximum of 50 repetitions. All the exercises were carried out on the equipment developed by Joseph Pilates: Reformer, Cadillac, Barrel, Step-chair and Wall-unit, plus some accessories such as: Swiss ball, elastic bands, to nig-boll, balance board and magic circulate as previously described..$^{21}$ Statistical analysis was performed using the PrismStat 5.0 program. Initially, a normality test was performed, which demonstrated normal data, thus making it possible to use the ANOVA One-Way with post-hoc of Tukey's for intragroup comparison with a sensitivity of $5 \%$.

\section{Results and discussion}

All values of the variables of interest in the present study varied as expected; however, waist circumference and WHtR of the CEG alone showed a significant difference among all the comparisons $(p<0.05)$, while the others were marginally significant. Figure 1 shows that the BMI of the CEG in the pretest was $29.4 \pm 4.52$ and in the post-test $28.2 \pm 3.65$ and of the CG in the pretest $29.90 \pm 4.5$ and in the post-test $28.11 \pm 4.1$. The BAI of the CEG in the pre-test was $29.67 \pm 3.65 \%$ and in the post-test $28.39 \pm 3.83 \%$ and of the CG in the pretest $28.26 \pm 3.16 \%$ and in the post-test $26.56 \pm 3.62 \%$. In the pretest, the CEG showed a mean of $82 \pm 8.23 \mathrm{~cm}$ and in the post-test $75.3 \pm 7.45$ $\mathrm{cm}$ with a difference between the two comparisons $(\mathrm{p}<0.05)$; in the CG in the pretest $80.6 \pm 8.13 \mathrm{~cm}$ and in the post-test $78.4 \pm 7.45 \mathrm{~cm}$. For the WHtR, the CEG obtained in the pre-test $0.49 \pm 0.8$ and in the post-test $0.41 \pm 0.1$ also showing a difference $(\mathrm{p}<0.05)$ and in the CG in the pretest $0.48 \pm 0.09$ and in the post-test $0.46 \pm 0.08$. The other measurements showed no difference from the pre- to the post-test and were marginally significant.

The main aim of the present study was to investigate whether the addition of ten minutes of continuous cardiovascular training with moderate intensity could modify the effects of Pilates training on body composition and measures of central fat distribution. To do this, some procedures were carried out, such as measuring height, body mass, waist circumference and calculating the waist-to-weight ratio, Body Adiposity Index and Body Mass Index. The comparison of effects after sixteen weeks of training aimed to increase the probability of detecting the possible relationship between the systematic practice of Pilates with or without the addition of ten minutes of continuous cardiovascular training and its possible effect on body composition and central fat distribution. The Academy of Nutrition and Dietetics, Dietitians of Canada and the American College of Sports Medicine establishes adequate fat percentages by age group considering health issues. Within the average age of the subjects analyzed, the percentages established by the agency are women aged 20 to 29 years: $20 \%$; Women aged 30 to 39 years: $21 \%$; Women aged 40 to 49 years: $22 \%$; Women between 50 and 59 years of age: $23 \%{ }^{21}$ In this sense, the data found here demonstrate a tendency, though not significant, to modify the body composition of adults of both sexes, with evidence that waist circumference and WHtR decreased. The data presented here seem to indicate that the inclusion of ten minutes of cardiovascular exercise is an effective strategy to modify body composition and fat accumulation in the central region of the body.

Our data if compared with another literature data has partial concordance with the contemporaneous authors show that the weight, BMI, fat percentage, waist, abdomen and hip circumference decreased significantly after training ${ }^{15,16,22} \quad(\mathrm{P}<0.05)$ while no significant difference was observed in lean body mass $(\mathrm{P}>0.05)$, data corroborated by another works. ${ }^{20,23,24}$ Here, our data showed that the 
qualitative investigations as waist, hip circumference decrease but not the weight, BMI or FAT mass. This data is important due this two points are more associated with cardiovascular diseases than the fat mass or BMI. But, in another hand, this data corroborates what was previously published by our group that demonstrated that body fat
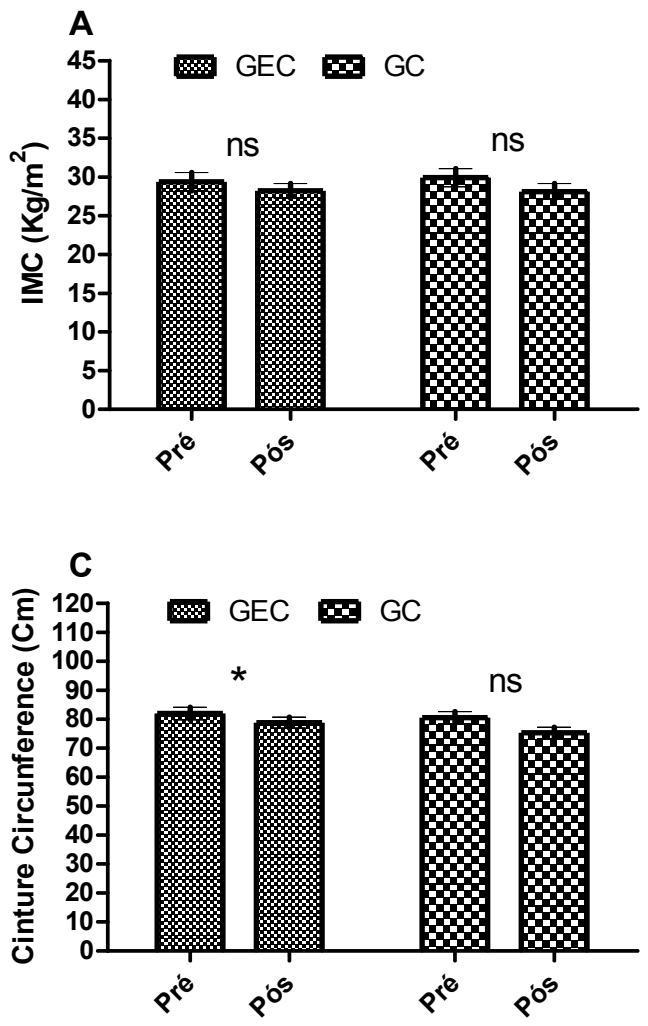

Figure I Comparison data for the CEG and CG pre- and post-tests of the variables studied in the present study.

composition was not modified due of the Pilates training. ${ }^{15,20}$ Thus, following what was described in present work, our approach, do not was able in enhance the effectiveness of Pilates method in decrease the body fat.
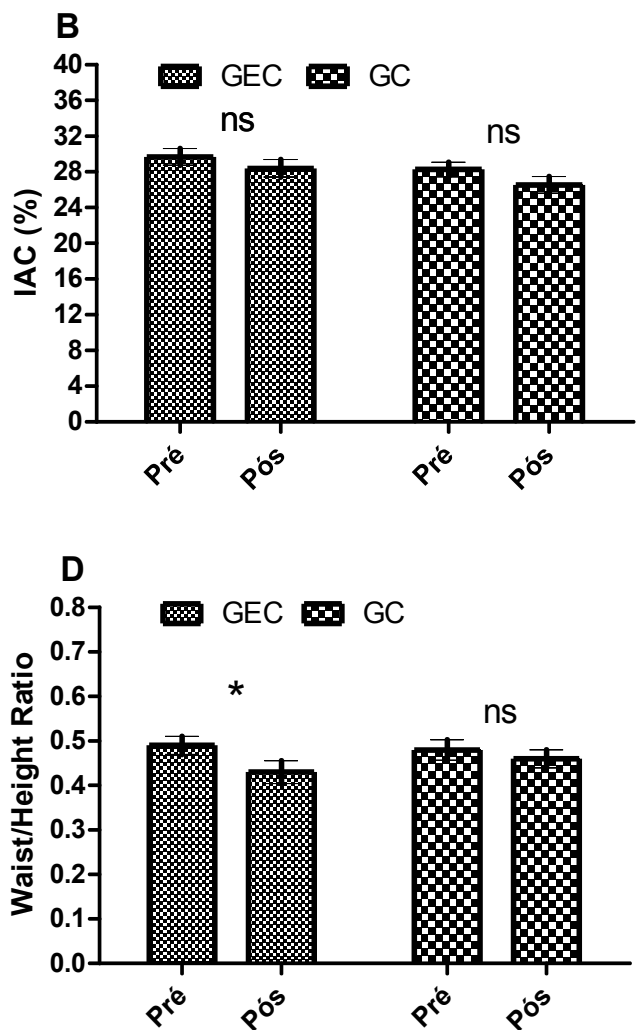

A. BMI, body mass index; B. BAl, body adiposity index; C. waist circumference; D. waist-to-height ratioA; Kg/M²: kilogram per square meter; B\%, percentage; C, Cm: centimeter; (A,B,C \& D Ns: not significant); (C\&D*, difference of $P<0.05$ in the pre- $X$ post-test)

\section{CEG, cardiovascular experimental group (N: I5); CG, control group (N: I5)}

The mean fat concentration decreased in the studied groups. Here the data do not corroborate with Lima who compared the effects of the Pilates method with bodybuilding was identified that the Pilates method in adolescents at the beginning of puberty has a positive effect on BMI. Still, points to physical activity allied with food control as an excellent method for body composition modification, ${ }^{16}$ agreeing in part with the findings of this study and other studies that have shown beneficial effects of the Pilates method on different aspects of. ${ }^{9,24,25}$ States that weight control and exercise are capable of reversing the association of factors that can lead to illnesses and even death, highlighting the importance of the data found here..$^{22}$

One study with 47 subjects undergoing Pilates training for six months, stated that effects on body composition and health are limited, ${ }^{4}$ but in the present study, Pilates appears to have been able to modify body composition and factors related to health and quality of life. In the same context, knowing that waist circumference outside the recommended level is indicative of an increased chance of developing diabetes mellitus ${ }^{16}$ and risk factors for cardiovascular accidents. ${ }^{13,26}$ However, the data from this study point to the Pilates Method as capable of decreasing waist circumference, proving this method to be important for human health.

Human health scholars infer that body mass and composition are related to different aspects of human health such as cancer, ${ }^{27}$ quality of life, ${ }^{28}$ cardiometabolic health, ${ }^{7}$ diabetes mellitus, ${ }^{6}$ sleep and mood quality, ${ }^{25}$ mental health. ${ }^{29}$ Central fat distribution is an important aspect for human health since it is related to several aspects of human health, such as insulin resistance, diabetes, visceral fat and hypertension. ${ }^{3,13}$

\section{Conclusion and perspectives}

The data found here suggest that the Pilates method associated with cardiovascular training was able to modify the WHtR and waist circumference. When taken together, data from the present study demonstrate the effectiveness of the Pilates Method in modifying body composition, fat accumulation in the central region with important significance for human health. Finally, this study emphasizes that the addition of ten minutes of moderately intense continuous cardiovascular training to the Pilates method is able to modify body composition and performance suggesting effectiveness and applicability of this modification as an effective alternative over the variables investigated herein. 


\section{Acknowledgements}

None.

\section{Conflict of interest}

This manuscript does not have conflict of interest.

\section{References}

1. Gandhi PK, Revicki DA, Huang IC. Adolescent body weight and health-related quality of life rated by adolescents and parents: The issue of measurement bias Energy balance-related behaviors. BMC Public Health. 2015;15(1):1192.

2. Neil CE, Fulgoni VL, Nicklas TA. Tree Nut consumption is associated with better adiposity measures and cardiovascular and metabolic syndrome health risk factors in U.S. Adults: NHANES 2005-2010. Nutr J. 2015;14(1):64.

3. Ashwell M, Gunn P, Gibson S. Waist-to-height ratio is a better screening tool than waist circumference and BMI for adult cardiometabolic risk factors: Systematic review and meta-analysis. Obes Rev. 2012;13(3):275-286.

4. Afdhal NH. Management of nonalcoholic fatty liver disease. A 60-yearold man with probable nonalcoholic fatty liver disease: Weight reduction, liver biopsy, or both? JAMA. 2012;308(6):608-616.

5. Ringseis R, Eder K, Mooren FC, Krüger K. Metabolic signals and innate immune activation in obesity and exercise. Exerc Immunol Rev. 2015;21:58-68.

6. Bays HE. Adiposopathy, diabetes mellitus, and primary prevention of atherosclerotic coronary artery disease: Treating "sick fat" through improving fat function with antidiabetes therapies. Am J Cardiol. 2012;110(S9):4B-12B.

7. Gillen JB, Martin BJ, MacInnis MJ, et al. Twelve weeks of sprint interval training improves indices of cardiometabolic health similar to traditional endurance training despite a five-fold lower exercise volume and time commitment. PLoS One. 2016;11(4):e0154075.

8. Dennis RA, Ponnappan U, Kodell RL, et al. Immune Function and Muscle Adaptations to Resistance exercise in Older Adults: Study Protocol for a Randomized Controlled Trial of a Nutritional Supplement. Trials. 2015;16(1):121.

9. Straznicky NE, Lambert EA, Grima MT, et al. The effects of dietary weight loss with or without exercise training on liver enzymes in obese metabolic syndrome subjects. Diabetes Obes Metab. 2012;14(2):139-148.

10. Perandini LA, Oliveira SD, Mello S, et al. Inflammatory cytokine kinetics to single bouts of acute moderate and intense aerobic exercise in women with active and inactive systemic lupus erythematosus. Exerc Immunol Rev. 2015;21:174-185.

11. Gould DW, Lahart I, Carmichael AR, et al. Cancer cachexia prevention via physical exercise: molecular mechanisms. J Cachexia Sarcopenia Muscle. 2013;4(2):111-124.

12. Swift DL, Lavie CJ, Johannsen NM, et al. Physical Activity, Cardiorespiratory Fitness and Exercise Training in Primary and Secondary Coronary Prevention. Circ J. 2013;77(2):281-292.

13. Nahar N, Dubey S, Joshi A, et al. Association of anthropometric indices of obesity with diabetes, hypertension and dyslipidemia: a study from central India. Indian J Med Spec. 2012;3(1):6-11
14. Tanaka H, Desouza CA, Jones PP, et al. Greater rate of decline in maximal aerobic capacity with age in physically active vs. sedentary healthy women. J Appl Physiol. 1997;83(6):1947-1953.

15. Cakmakci O. The effect of 8 week pilates exercise on body composition in obese women. Coll Antropol. 2001;35(4):1045-1050.

16. Jago R, Jonker ML, Missaghian M, et al. Effect of 4 weeks of Pilates on the body composition of young girls. Prev Med. 2006;42(3):177-180.

17. Silva DRA, Lunardello LFA, Oliveira DGL, et al. Ginástica geral pode melhorar a marcha e a capacidade cardiovascular de idosos. Rev Bras Med do Esporte. 2016;22(4):306-310.

18. Silva VJR, Costa ML, Oliveira GL, et al. High Intensity Exercise and Flexibility of the Lower Limbs: Dose-Effect Study. Rev Bras Med do Esporte. 2016;22(4):311-314.

19. Oliveira GL, Oliveira TAP, Gonçalves PS, et al. Body image and eating disorders in female athletes of different sports. J Exerc Physiol. 2017;20(2):44-54

20. Nogueira TRB, Oliveira GL, Oliveira TAP, et al. Efeito do método Pilates nas adaptações neuromusculares e na composição corporal de adultos jovens. Rev Bras Prescrição e Fisiol do Exerc. 2014;8(45):296-303.

21. Thomas DT, Erdman KA, Burke LM. Position of the Academy of Nutrition and Dietetics, Dietitians of Canada and the American College of Sports Medicine: Nutrition and Athletic Performance. J Acad Nutr Diet. 2016;116(3):501-528.

22. Segal NA, Hein J, Basford JR. The effects of pilates training on flexibility and body composition: An observational study. Arch Phys Med Rehabil. 2004;85(12):1977-1981.

23. Lowres N, Neubeck L, Freedman SB, et al. Lifestyle risk reduction interventions in atrial fibrillation: A systematic review. Eur J Prev Cardiol. 2012;19(5):1091-1100.

24. Ferreira CA, Fernandes J, Laranjo L, et al. A systematic review of the effects of pilates method of exercise in healthy people. Arch Phys Med Rehabil. 201;92(12):2071-2081.

25. Caldwell K, Harrison M, Adams M, et al. Effect of Pilates and taiji quan training on self-efficacy, sleep quality, mood and physical performance of college students. J Bodyw Mov Ther. 2009;13(2):155-163.

26. Wang Z, Rowley K, Wang Z, et al. Anthropometric indices and their relationship with diabetes, hypertension and dyslipidemia in Australian Aboriginal people and Torres Strait Islanders. Eur J Prev Cardiol. 2007;14(2):172-178.

27. Purcell SA, Elliott SA, Kroenke $\mathrm{CH}$, et al. Impact of Body Weight and Body Composition on Ovarian Cancer Prognosis. Curr Oncol Rep. 2016;18(2):1-11.

28. Czajka K, Kołodziej M. Parental Perception of Body Weight in Preschool Children and an Analysis of the Connection Between Selected ParentRelated Factors and the Assessment of Their Children'S Weight. Dev period Med. 2015;19(3 Pt 2):375-382.

29. Avila C, Holloway AC, Hahn MK, et al. An Overview of Links Between Obesity and Mental Health. Curr Obes Rep. 2015;4(3):303-310. 